\title{
General Practitioners' willingness to Pay for Continuing Medical Education in a Fee-for-service Universal Coverage Health Care System
}

\author{
Shahzia Lambat Emery ${ }^{1^{*}}$, Reto Auer ${ }^{1,2}$, Nicolas Senn ${ }^{1}$, Isabella Locatelli ${ }^{1,3}$ and Jacques Cornuz ${ }^{1}$ \\ ${ }^{1}$ Department of Ambulatory Care and Community Medicine, University of Lausanne, Switzerland \\ ${ }^{2}$ Department of Epidemiology and Biostatistics, University of California, San Francisco, USA \\ ${ }^{3}$ Department of Social and Preventive Medicine, University of Lausanne, Switzerland
}

*Corresponding author: Shahzia Lambat Emery, Policlinique Médicale Universitaire, Rue du Bugnon 44, 1011 Lausanne, Switzerland, Tel: 0041786561022; E-mail: Shahzia.LambatEmery@hcuge.ch

Received date: March 31, 2014; Accepted date: Sept 2, 2014; Published date: Sept 8, 2014

Copyright: $\odot 2014$ Emery SL, et al. This is an open-access article distributed under the terms of the Creative Commons Attribution License, which permits unrestricted use, distribution, and reproduction in any medium, provided the original author and source are credited.

\begin{abstract}
Background: Sponsoring of medical meetings by life science companies has led to reduced participation fees for physicians but questions potential drawbacks. Ongoing discussions are proposing to ban such sponsoring which may increase participation fees.
\end{abstract}

Objectives: To evaluate factors associated with general practitioners' willingness to pay for medical meetings, their support of a binding legislation prohibiting sponsoring and their opinion on alternative financing options.

Methods: An anonymous web-based questionnaire was sent to 447 general practitioners' of one state in Switzerland, identified through their affiliation to a medical association.

Results: Of the 115 physicians answering, $48 \%$ were willing to pay more than what they currently pay for medical meetings and $79 \%$ disagreed that sponsoring introduced a bias in their own prescription practices. In univariate analyses, factors most associated with physician's willingness to pay were perception of a bias in peers prescription practices (OR=6.67; 95\% Cl: 1.60-27.74), group practice $(\mathrm{OR}=3.01 ; 95 \% \mathrm{Cl}: 0.94-9.65)$ and having <4 meetings with sales representatives per month (OR=2.39; $95 \% \mathrm{Cl}$ : $0.91-6.33)$. $78 \%$ did not support the introduction of a binding legislation and $56 \%$ were in favor of creating a general fund set up by life science companies and centrally administered by an independent body as an alternative financing option.

Conclusions: Our results suggest that almost half of physicians surveyed were willing to pay more than what they currently pay for medical meetings and that an independent body that would centrally administer a general fund set up by life science companies might be better received by general practitioners' than a legislation banning the sponsoring of medical meetings by life science companies.

Keywords: Medical education; Ethics; Health policy; General practice

\section{Abbreviations \\ CME: Continuing Medical Education; WTP: Willingness to pay}

\section{Introduction}

Life science companies (e.g., pharmaceutical and health technology companies) are a very important sector of Switzerland's economy with 2010 sales representing $\$ 57$ billion [1]. Not only do they have an economic benefit but they also provide doctors and patients worldwide with continual therapeutic progresses. Nevertheless, due to a few but significant unexpected adverse effects related to the use of approved drugs (i.e. rofecoxib [2]), and in order to increase patient security, legal requirements to obtain marketing approval have become more demanding, resulting in the lengthening of the development processes and declining research and development productivity [3].
One way life science companies have responded to these challenges has been by using marketing strategies such as the sponsoring of physicians' continuing medical education (CME). This strategy can be used throughout a products' life cycle to facilitate product visibility and utilization, thus representing a marketing strategy with high return on investment potentials $[4,5]$.

Currently, in Switzerland, physicians have the obligation to acquire 80 annual CME credits. Two-thirds of these CME credits have to be acquired in the form of structured CME (e.g. medical meetings, seminars and conferences) while the remaining third can be acquired through self-study [6]. Most medical meetings are partially or fully sponsored by life science companies, resulting in lower participation fees for physicians. Ongoing discussions in the medical literature are questioning whether this form of industrial marketing does not lead to potential drawbacks including conflict of interest as well as direct and indirect commercial products promotion through altered disease management and prescribing habits bias [7], possibly contributing to the rise of national health costs $[8,9]$. This question is even more relevant in Switzerland, a country with a health care system combining fee for service and universal health insurance coverage, and where 
national health costs accounted for $10.8 \%$ of GDP in 2010 and are estimated at $11.9 \%$ of GDP in 2016 [1].

There are currently no laws in Switzerland regulating the sponsoring of physicians' CME. In 2011, a Federal Councillor proposed to introduce a legislation banning the sponsoring of physicians medical meetings by life science companies which most certainly would result in the increase in physicians' participation fees [10]. We wanted to evaluate factors associated with general practitioners (GPs') willingness to pay (WTP) for medical meetings, their position on the sponsoring of $\mathrm{CME}$ and their opinion on alternative financing options.

\section{Methods}

\section{Study population}

The survey was conducted in the State of Vaud in Switzerland (721'561 inhabitants estimated at the end of 2011 [11]), where an anonymous web-based created questionnaire (Survey Methods ${ }^{\circ}$, Allen, Texas) was sent out to 447 GPs'. The 447 GPs were selected based on their membership to the association of Swiss Family Doctors, representing the leading association in terms of affiliated physicians' in the State of Vaud (convenience sample). The association sent the hyperlink of the questionnaire and two reminders via their mailing list. Physicians were free to answer at their convenience between the $13^{\text {th }}$ July and the $14^{\text {th }}$ August 2011.

\section{Survey questionnaire}

A questionnaire comprising a total of 21 questions was developed in a consensus group based existing questions found in the medical literature [12-14] and those used by the Swiss Medical Association (Foederatio Medicorum Helveticorum, FMH) for their statistics. The questionnaire was pilot tested with 10 chief residents from the Department of Ambulatory Care and Community Medicine of the University of Lausanne (State of Vaud) and with 10 GPs' from other French-speaking States (Fribourg, Neuchatel and Valais) to evaluate the overall comprehension of the questions and to test the relevance of our questions (face validity). Two questions were modified based on the pilot test of the questionnaire. The 10 chief residents and the 10 GPs' who participated in the pilot test were not part of the study population when the study was conducted.

The first part of the questionnaire determined physicians' socioeconomic characteristics using multiple choice questions. The questionnaire then targeted three main areas: (1) physicians' WTP for CME, (2) physicians' position on the sponsoring of CME by life science companies and (3) physicians' opinion on alternative financing options to support their CME. Physicians' WTP was evaluated using two types of questions. An open-ended question was used to quantify their global WTP for half a day of CME ( 4 hours of CME equivalent to 4 credits) and a multiple choice question was used to evaluate their WTP for half a day of each CME category with 5 possible answers (i.e., " $\geq$ CHF150", "CHF100-149", "CHF50-99", "<CHF50", "I am not prepared to pay for this category of CME"; $1 \mathrm{CHF}=1 \mathrm{EUR}$ [15]). We also used an open-ended question to quantify physician's perception of a two-day non-sponsored medical meeting participation fee given the participation fee of EUR310 to attend the two-day sponsored medical meeting of Swiss Family Docs, a highly attended sponsored medical meeting for Swiss GPs. Their opinion on the other items was evaluated using a four-point scale (i.e., 4 representing "strongly agree" and 1 "strongly disagree").

\section{Analysis}

Simple descriptive statistics were used to illustrate physicians' socioeconomic characteristics and to describe physicians' collective opinion on their WTP for CME, their perception of a bias in prescription practices induced by commercial support, their support of a binding legislation and their opinion on alternative financing options. To evaluate factors associated with physicians' WTP for medical meetings, WTP was dichotomised into EUR $\geq 150$ and EUR $<150$, EUR $\geq 150$ representing the category of physicians willing to pay the highest fees for medical meetings based on the 5 possible answers to our multiple choice question evaluating physicians' WTP for each CME category. Univariate logistic regression analyses were ran with WTP for medical meetings as the outcome. Variables tested were age, sex, full-time/part-time, annual income, practice location, practice structure, health maintenance organization membership, number of meetings with sales representatives per month, average time spent per meeting, number of sponsored medical meetings attended in 2010, perception of a bias in own prescription practices induced by commercial support and perception of a bias in peers prescription practices induced by commercial support (i.e. some responding $G P s^{\prime}$ felt some of their peers prescribing habits could be influenced by attending sponsored meetings). These variables were chosen in a consensus group and using those tested in the medical literature [11-13]. Statistical analyses were performed using Stata version 12 (Stata Corporation, TX).

\section{Ethics}

The study protocol was approved by the ethics committee of the University of Lausanne, Switzerland, decision number 52/13. Information concerning this study was disclosed by email to physicians with a study participation that was voluntary and anonymous.

\section{Results}

\section{Physicians' socioeconomic characteristics}

Of the 447 physicians contacted, 115 questionnaires $(\mathrm{N}=115)$ were completed through the online survey (response rate of 26\%). A majority of the respondents were male (72\%) with a mean age of 53 years 6 (Table 1). 52\% of physicians worked part-time ( $4 \%$ worked 5 half days or less per week and 48\% worked in between 6 and 9 half days per week). Annual income before tax was less than EUR160'000 for $63 \%$ of physicians. The majority (53\%) of physicians working fulltime earned $\geq E U R 160$ '000 and $63 \%$ of physicians working part-time earned in between EUR80'000 and EUR159'999. Their practices were majorly located in small towns (41\%) followed by rural villages (35\%) and large cities (24\%). 63\% worked in group practices and 30\% were member of a health maintenance organization. $56 \%$ of physicians met up with sales representatives $\geq 4$ times per month and $64 \%$ spent 15 minutes or less per meeting. $35 \%$ of physicians did not attend any sponsored medical meetings in 2010 in comparison with $33 \%$ who attended 1 to 3 sponsored medical meetings and $34 \%$ who attended 4 sponsored medical meetings or more. 
Citation: Emery SL, Auer R, Senn N, Locatelli I, Cornuz J (2014) General Practitioners' willingness to Pay for Continuing Medical Education in a

Page 3 of 6

\section{Physicians' WTP for CME}

The mean $( \pm$ SD) WTP was EUR105 $( \pm 71)$ for half a day of CME (e.g. medical meetings, seminars and conferences), $27 \%$ of physicians were willing to pay $\geq E U R 150,34 \%$ were willing to pay in between EUR100 and EUR149 and 39\% were willing to pay $<$ EUR100 for half a day of CME (Figure 1). $48 \%$ of physicians were willing to pay $\geq$ EUR100 for medical meetings ( $18 \%$ were willing to pay EUR $\geq 150$ and $30 \%$ were willing to pay in between EUR100 and EUR149) with medical meetings being an important category of CME for $96 \%$ of physicians.

We also assessed physician's cost estimate of a two-day medical meeting that would not be sponsored by life science companies. The mean $( \pm \mathrm{SD})$ cost estimate was EUR799 $( \pm 312)$, corresponding to an increase of $58 \%$ in comparison to Swiss Family Docs' current participation fee of EUR310.

\begin{tabular}{|c|c|c|c|}
\hline Variable & No $(\mathrm{N}=115)$ & Percentage & $\begin{array}{l}\text { Comparison with } \\
\text { FMH }^{\star} \text { statistics }\end{array}$ \\
\hline $\begin{array}{l}\text { Age mean(Standard } \\
\text { Deviation) }\end{array}$ & $53(8)$ & & 53 \\
\hline \multicolumn{4}{|l|}{ Sex } \\
\hline Male & 83 & $72 \%$ & $68 \%$ \\
\hline Female & 32 & $28 \%$ & $32 \%$ \\
\hline \multicolumn{4}{|l|}{ Full-time/part-time ${ }^{*}$} \\
\hline Full-time & 55 & $48 \%$ & $43 \%$ \\
\hline Part-time & 60 & $52 \%$ & $57 \%$ \\
\hline \multicolumn{4}{|l|}{ Income per year } \\
\hline EUR<160'000 & 72 & $63 \%$ & $37 \%$ \\
\hline$E U R \geq 160 ' 000$ & 43 & $37 \%$ & $63 \%$ \\
\hline \multicolumn{4}{|l|}{ Practice location ${ }^{* *}$} \\
\hline Large city & 28 & $24 \%$ & n.a. \\
\hline Small town & 47 & $41 \%$ & n.a. \\
\hline Rural village & 40 & $35 \%$ & n.a. \\
\hline \multicolumn{4}{|l|}{ Practice structure } \\
\hline Group & 72 & $63 \%$ & $43 \%$ \\
\hline Individual & 43 & $37 \%$ & $57 \%$ \\
\hline \multicolumn{4}{|l|}{$\begin{array}{l}\text { Health maintenance } \\
\text { organization }^{* \star \star} \\
\text { membership }\end{array}$} \\
\hline Yes & 35 & $30 \%$ & $34 \%$ \\
\hline \multicolumn{4}{|l|}{ 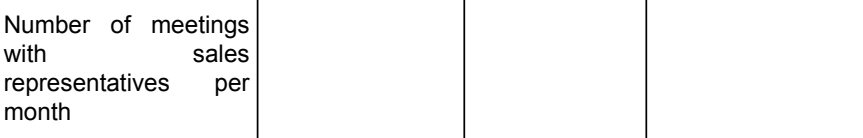 } \\
\hline 0 & 12 & $10 \%$ & n.a. \\
\hline $1-3$ & 39 & $34 \%$ & n.a. \\
\hline $4-10$ & 56 & $49 \%$ & n.a. \\
\hline
\end{tabular}

\begin{tabular}{|c|c|c|c|}
\hline$\geq 11$ & 8 & $7 \%$ & n.a. \\
\hline $\begin{array}{lr}\text { Average time } & \text { spent } \\
\text { with } & \text { sales } \\
\text { representatives } & \text { per } \\
\text { meeting } & \end{array}$ & & & \\
\hline$<16$ minutes & 74 & $64 \%$ & n.a. \\
\hline$\geq 16$ minutes & 41 & $36 \%$ & n.a. \\
\hline $\begin{array}{l}\text { Number of sponsored } \\
\text { medical meetings } \\
\text { attended in } 2010\end{array}$ & & & \\
\hline 0 & 40 & $35 \%$ & n.a. \\
\hline $1-3$ & 38 & $33 \%$ & n.a. \\
\hline $4-10$ & 29 & $25 \%$ & n.a. \\
\hline$\geq 11$ & 8 & $7 \%$ & n.a. \\
\hline
\end{tabular}

Table 1: Physicians' socioeconomic characteristics.

Abbreviation of FMH: Foederatio Medicorum Helveticorum (Swiss Medical Association), n.a.: non-available.

${ }^{*}$ Part-time: corresponds to an activity rate of 9 half days or less.

${ }^{* *}$ Large city: $\sim 130$ '000 inhabitants, small town: $~ 18^{\prime} 000$ inhabitants and rural village: $\sim 3{ }^{\prime} 000$ inhabitants.

${ }^{* * *}$ Health maintenance organizations are managed care plans that provide health care services to their members through networks of doctors, hospitals, and other health care providers. (Source: Texas Department of Insurance, http://www.tdi.texas.gov/pubs/consumer/ cb069.html, accessed at 20.08.2013).

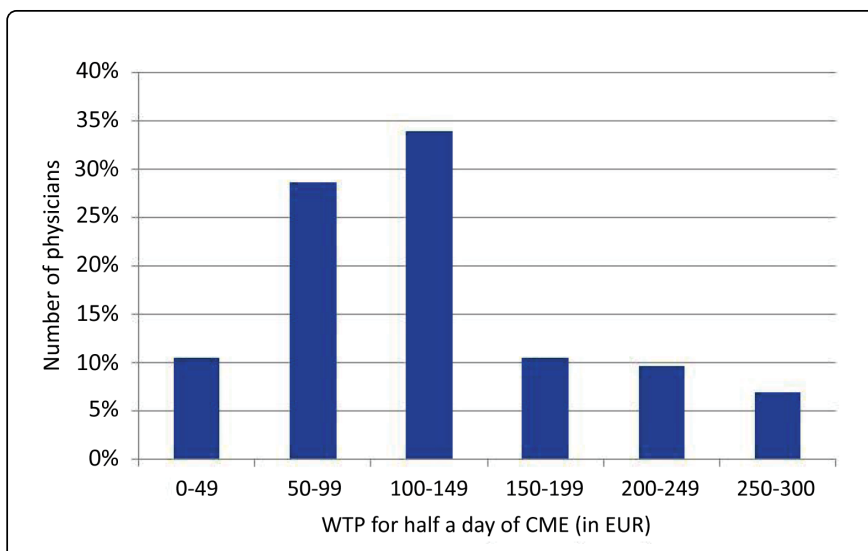

Figure 1: Self-reported physicians' willingness to pay (WTP) for half a day of continuing medical education ${ }^{*}(\mathrm{CME})$.

\section{Variables associated with physicians' WTP for medical meetings}

The univariate logistic regression showed three variables associated with physicians' WTP $\geq$ EUR150 for medical meetings (all $p<0.1$ ): the perception of bias in peers prescription practices, "strongly agree" vs. "agree, disagree, or strongly disagree" (OR=6.67; 95\%CI: 1.60-27.74); the practice structure, group vs. individual $(\mathrm{OR}=3.01 ; 95 \% \mathrm{CI}$ : 
Citation: Emery SL, Auer R, Senn N, Locatelli I, Cornuz J (2014) General Practitioners' willingness to Pay for Continuing Medical Education in a Fee-for-service Universal Coverage Health Care System. J Gen Practice 2: 172. doi:10.4172/2329-9126.1000172

Page 4 of 6

0.94-9.65); and the number of meetings with sales representatives per month, $<4$ vs. $\geq 4$ (OR=2.39; 95\%CI: 0.91-6.33) (Table 2).

\section{Physicians' position on the sponsoring of CME}

$79 \%$ of physicians disagreed that sponsoring of their CME by life science companies influenced their own prescription practices and $61 \%$ disagreed that it introduced a bias in their colleagues' prescription practices. In terms of introducing a binding legislation prohibiting the sponsoring of CME by life science companies, $78 \%$ of physicians would not support it and $77 \%$ did not think that such draft legislation was likely to be enacted.

\begin{tabular}{|l|l|l|}
\hline Variable & OR $(95 \%$ CI) & p-value \\
\hline $\begin{array}{l}\text { Perception of bias in peers prescription } \\
\text { practices* }\end{array}$ & $6.67(1.60-27.74)$ & 0.01 \\
\hline Group practice structure & $3.01(0.94-9.65)$ & 0.06 \\
\hline $\begin{array}{l}<4 \text { meetings with sales representatives } \\
\text { per month }\end{array}$ & $2.39(0.91-6.33)$ & 0.08 \\
\hline Annual income $\geq E U R 160$ '000 & $2.13(0.82-5.55)$ & 0.12 \\
\hline $\begin{array}{l}<16 \text { minutes spent per meetings with } \\
\text { sales representatives }\end{array}$ & $1.99(0.67-5.89)$ & 0.22 \\
\hline Male sex & $1.80(0.56-5.84)$ & 0.33 \\
\hline $\begin{array}{l}\geq 4 \text { sponsored medical meetings } \\
\text { attended in } 2010\end{array}$ & $1.77(0.67-4.67)$ & 0.25 \\
\hline
\end{tabular}

\begin{tabular}{|l|l|l|}
\hline Working Full-time & $1.58(0.61-4.11)$ & 0.35 \\
\hline $\begin{array}{l}\text { Perception of a bias in own prescription } \\
\text { practices* }^{*}\end{array}$ & $1.50(0.15-15.18)$ & 0.73 \\
\hline $\begin{array}{l}\text { Practice located in small towns or rural } \\
\text { villages }\end{array}$ & $1.46(0.45-4.76)$ & 0.53 \\
\hline $\begin{array}{l}\text { Not member of a health maintenance } \\
\text { organization }\end{array}$ & $1.12(0.39-3.17)$ & 0.84 \\
\hline Age & $1.02(0.96-1.07)$ & 0.61 \\
\hline
\end{tabular}

Table 2: Factors associated with physicians' willingness to pay (WTP) for medical meetings in univariate logistic regression models.

Abbreviations: OR, odds ratio; CI, confidence interval.

${ }^{*}$ Perception of bias in peers prescription practices dichotomized as "strongly agree" vs. "agree, disagree, strongly disagree" on a 4 item like rt scale.

\section{Physicians' opinion on alternative financing options}

A majority of physicians were in favour of a financing through a levy on medical services (65\%) instead of direct sponsorship to support CME. 56\% were in favour of financing through a general fund set up by life science companies and centrally administered by an independent body, 55\% agreed to government financing and $65 \%$ were unfavourable to self-funding by physicians (Figure 2).

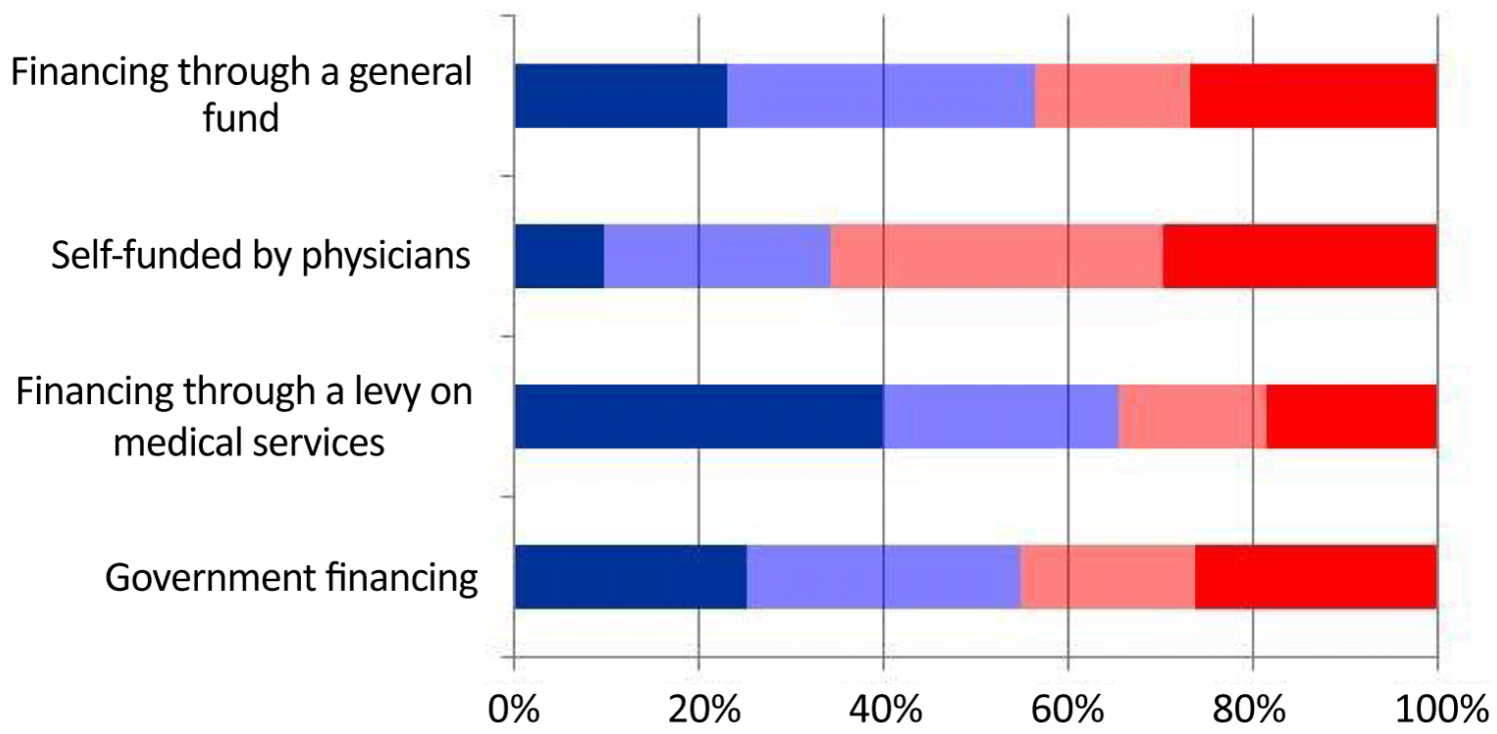

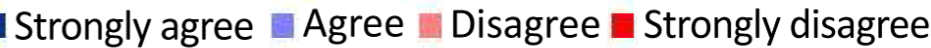

Figure 2: Physicians' opinion on alternative financing options.

\section{Discussion}

Our study shows that $48 \%$ of GPs' in the surveyed population were willing to pay $\geq E U R 100$ for half a day of medical meetings, a category of CME that $96 \%$ of surveyed physicians rated as important. Given the current participation fee of 80EUR for half a day of medical meeting, our results suggest that physicians are willing to pay more than what they currently pay for medical meetings. Variables associated with 
physicians' WTP for medical meetings in univariate analyses, i.e. a WTP $\geq$ EUR150, were perception of the influence of bias in peers' prescription practices, group practice structure and $<4$ meetings with sales representatives per month.

An on CME site survey study conducted by Tabas et al. in the US found that $42 \%$ of medical professionals (physicians, nurses, nurse practitioners and physician assistants) were willing to pay higher fees to decrease or eliminate commercial support, $88 \%$ believed that commercial support introduced a bias and $85 \%$ did not support the elimination of commercial support from CME activities [16]. Our study adds to previous work by quantifying physicians' WTP for CME and highlights characteristics associated with physicians' WTP for medical meetings.

Prior studies have shown that life science companies influence physicians prescribing habits in ways that physicians do not recognize. Indeed, physicians feeling valued by life science companies often unconsciously reciprocate this valorisation by using their therapeutic products [17]. In our survey, $56 \%$ of physicians meet up with sales representatives four times or more per month. Furthermore, 79\% of physicians disagreed that sponsoring influenced their own prescribing habits and $61 \%$ of physicians disagreed that sponsoring influenced their colleagues prescribing habits demonstrating an optimistic bias. Therefore, physicians' empowerment through prescribing bias awareness and independent decision making skills would potentially help physicians manage their collaboration with life science companies. This could not only help reduce potential influence of life science companies on physicians without modifying current sponsoring, but it could also possibly increase physicians WTP for medical meetings. Physicians who see sales representatives more often tend to be those who are more isolated from their colleagues [18]. Tentative explanations, although not tested in our analyses, would be that physicians in group practice rely less on sales representatives to learn about novel drugs or that they go through more peer pressure not to meet up with sales representatives. Given the current trend towards an increase in group practice structures [19], there might be an increase in physicians WTP for medical meetings in the future and a shift in the way physicians value their CME from a model relying on sales representatives to a model relying on medical meetings and group learning.

Although $78 \%$ of physicians were not in favour of a legislation prohibiting the sponsoring of medical meetings by life science companies, physicians agreed to a levy on medical services (65\%), a general fund set up by life science companies and centrally administered by an independent body (56\%) and government financing (55\%). Both a levy on medical services and government financing would increase national health costs already accounting for $11.7 \%$ of GDP in 2011 [1]. The alternative of a general fund therefore seems the most appropriate option to begin with. Nevertheless, this proposition would need to have an acceptable return on investment for life science companies to adhere to this alternative sponsoring option. Further research assessing life science companies' opinion needs to be undertaken.

Unlike the US where the question of CME sponsoring by life science companies and conflict of interest issues have been addressed for over 30 years [20] and regulated by the Sunshine Act, the situation in Switzerland is still in its early stages, possibly explaining low prescription bias perception found in our study. Currently, there are very few discussion and no laws that regulate the sponsoring of CME by life science companies. Recommendations on the collaboration between the medical cooperation and life science companies were edited for the first time in 2002 by the Swiss Academy of Medical Sciences (SAMS). These recommendations now stand as guidelines for physicians to obtain their 50 annual mandatory structured CME credits. A seven criteria checklist is used to ensure objectivity and transparency of a medical meeting for its credits to be validated as CME [21].

Several limitations must be taken into account when assessing the implications of our findings. The response rate was low, potentially limiting the validity of our findings, and we involved physicians from one State of Switzerland which had also to be part of the association of Swiss Family Doctors; thus generalization to all GPs' in Switzerland may be erroneous. However, despite these limitations, the socioeconomic characteristics of the surveyed physicians are similar to those of the Swiss Medical Association (Foederatio Medicorum Helveticorum, FMH), representing the target population; except for income per year and practice structure. CME requirement and programs vary amongst different specialties, making our observations difficult to generalize to other medical specialities. The survey relied on self-reported behaviour, potentially misestimating reality. Further studies should be undertaken to investigate physicians' WTP on a national basis in order to confirm our conclusions.

\section{Conclusion}

In conclusion, this study shows that almost half of general practitioners were willing to pay more than what they currently pay for medical meetings and that most respondents did not agree that sponsoring induced prescribing bias. For decision makers willing to regulate the mutual dependence of physicians and life science companies, rather than a legislation banning the sponsoring of medical meetings by life science companies which would increase physicians participation fees, an independent body that would centrally administer a general fund set up by life science companies to various medical meetings might be better received by surveyed physicians whilst maintaining health costs at an affordable level.

\section{Authors' Contributions}

SLE, RA, NS and JC made the conception and the design of the study, made the analyses and interpretations and revised the paper. IL built the univariate logistic regression model. SLE collected the data and did the main part of the writing. All have given a final approval of the version to be published.

\section{Acknowledgement}

Our findings were presented at 35th annual meeting of the Society of General Internal Medicine in Orlando, at the 2nd medical meeting of Swiss Family Docs in Lausanne and at the symposium of the Swiss Academy of Medical Sciences in Berne [22].

We would like to thank the participating general practitioners for their contributions to this study and the association of Swiss Family Doctors for their support.

Nicolas Senn is supported by an academic "bridge-relève" scholarship provided by the Leenaards Foundation (Lausanne, Switzerland). 
Citation: Emery SL, Auer R, Senn N, Locatelli I, Cornuz J (2014) General Practitioners' willingness to Pay for Continuing Medical Education in a Fee-for-service Universal Coverage Health Care System. J Gen Practice 2: 172. doi:10.4172/2329-9126.1000172

Page 6 of 6

\section{References}

1. BMI: Switzerland Pharmaceuticals \& Healthcare Report - Q3 (2012).

2. Jüni P, Nartey L, Reichenbach S, Sterchi R, Dieppe PA, et al. (2004) Risk of cardiovascular events and rofecoxib: cumulative meta-analysis. Lancet 364: 2021-2029.

3. PriceWaterhouseCoopers: Pharma 2020: Virtual R\&D - Which path will you take? (2008).

4. Brennan R, Eagle L, Rice D (2010) Medicalization and Marketing. Journal of Macromarketing 30: 8-22.

5. Rod M, Ashill NJ, Carruthers J (2007) Pharmaceutical marketing returnon-investment: a European perspective. International Journal of Pharmaceutical and Healthcare Marketing 1: 174-189.

6. Official website of the Foederatio Medicorum Helveticorum(2013).

7. Wazana A (2000) Physicians and the pharmaceutical industry, is a gift ever just a gift? JAMA 283: 373-380.

8. Watkins C, Moore L, Harvey I, Carthy P, Robinson E, Brawn R (2003) Characteristics of general practitioners who frequently see drug industry representatives: national cross sectional survey. BMJ 326: 1178-1179.

9. Gonul FF, Carter F, Petrova E, Srinivasan K (2001) Promotion of prescription drugs and its impact on physicians' choice behavior. J Marketing 65: 79-90.

10. Boder W (2011) La pharma ne devra plus financer les congrès médicaux. Le Temps.

11. Official website of the State of Vaud.

12. Campbell EG, Gruen RL, Mountford J, Miller LG, Cleary PD, et al. (2007) A national survey of physician-industry relationships. N Engl J Med 356: 1742-1750.
13. Prosser H, Walley T (2003) Understanding why GPs see pharmaceutical representatives: a qualitative interview study. Br J Gen Pract 53: 305-311.

14. Rutledge P, Crookes D, McKinstry B, Maxwell SRJ (2003) Do doctors rely on pharmaceutical industry funding to attend conferences and do they perceive that this creates a bias in their drug selection? Results from a questionnaire survey. Pharmacoepidemiol Drug Saf 12: 663-667.

15. UBS: Exchange rates on a rollercoaster ride - hedge currency risks?, Summer (2011).

16. Tabas JA, Boscardin C, Jacobsen DM, Steinman MA, Volberding PA, et al. (2011) Clinician attitudes about commercial support of continuing medical education: results of a detailed survey. Arch Intern Med 171: 840-846.

17. Somerset M, Weiss M, Fahey T (2001) Dramaturgical study of meetings between general practitioners and representatives of pharmaceutical companies; Commentary: dramaturgical model gives valuable insight. BMJ 323: 1481-1484.

18. Watkins C, Moore L, Harvey I, Carthy P, Robinson E, et al. (2003) Characteristics of general practitioners who frequently see drug industry representatives: national cross sectional study. BMJ 326: 1178-1179.

19. Foederatio Medicorum Helveticorum : Statistiques médicales 2008 de la FMH (2009). BMS 11: 455-461.

20. Avorn J, Chen M, Hartley R (1982) Scientific versus commercial sources of influence on the prescribing behavior of physicians. Am J Med 73: 4-8.

21. Académie Suisse des Sciences Médicales : «Checkliste» concernant l'attribution de Crédits pour les sessions de formation continue par les sociétés de discipline médicale.

22. Official website of the SwissFamilyDocs Conference. 